\title{
Construção colaborativa de sequência didática: uma ferramenta para o desenvolvimento da autoria docente e discente
}

\author{
Collaborative construction of didactic sequence: \\ a tool for the development of teacher and student authorship \\ Construcción colaborativa de secuencia didáctica: \\ una herramienta para el desarrollo de la autoría docente y discente \\ Fabiana Silva Soares Vieira ${ }^{2}$ \\ Ana Silvia Moço Aparício ${ }^{3}$
}

\begin{abstract}
Resumo: Neste artigo, discutimos resultados de uma pesquisa mais ampla em que investigamos o processo de construção colaborativa de uma sequência didática (SD), com o gênero textual "Carta ao autor", em uma classe de alfabetização de uma escola municipal de tempo integral, com vistas ao desenvolvimento das capacidades de linguagem e autoria dos alunos. Tendo como referencial teórico estudos desenvolvidos por pesquisadores do Grupo de Didática das Línguas de Genebra, nosso foco aqui é o processo formativo da professora alfabetizadora/colaboradora ao longo do planejamento e desenvolvimento da SD. A pesquisa é qualitativa de cunho colaborativo intervencionista e os dados considerados para análise são: registros em áudio das interações pesquisadora e professora colaboradora, gravação em vídeo das aulas, registros reflexivos em diário de campo da pesquisadora e as produções escritas realizadas pelos alunos. Os resultados indicam que a ferramenta SD contribuiu significativamente na constituição da autoria docente, bem como no desenvolvimento profissional das professoras colaboradora e pesquisadora.
\end{abstract}

Palavras-chave: Sequência didática de gênero textual. Alfabetização. Desenvolvimento profissional docente. Autoria docente. Carta ao autor.

\begin{abstract}
In this article, we discussed the results of a broader search in which we investigate the process of collaborative construction of a didactic sequence (DS) with the genre textual "letter to the author" in literacy class. In a full-time municipal school, focusing the development of the capacity of building language and authorship of the students. Having as theoretical reference developed studies by researchers from the Geneva Language Teaching Group, our focus here is the process of the literacy teacher/collaborator throughout the planning and development of DS. The research is qualitative in nature collaborative interventionist and the data considered for analysis are: records in audio of the interactions between researcher and collaborating teacher, video recording of the classes, reflexive records in the researcher's field diary and the productions written by students. The results indicate that the DS tool contributed significantly to the constitution of teaching authorship, as well as to professional development of the collaborating and researching teachers.
\end{abstract}

Keywords: Didactic sequence of textual genre. Literacy. Professional teacher development. Teaching authority. Letter to the author.

Resumen: En este artículo, se discuten los resultados de una encuesta más amplia en la que se investiga el proceso de construcción colaborativa de una secuencia didáctica (SD) con el género textual "carta a autor" en una clase de alfabetización de una escuela municipal de tiempo completo, con el fin de desarrollar las habilidades linguísticas y la autoría de los estudiantes. Teniendo como estudios teóricos de referencia desarrollados por investigadores del grupo de didáctica de las lenguas de Ginebra, nuestro enfoque aquí es el proceso formativo de la alfabetización/colaborador docente a lo largo de la planificación y desarrollo de la SD.

\footnotetext{
${ }^{1}$ Submetido em: 15 abr. 2018 - Aceito em: 26 set. 2018 - Publicado em: 08 fev. 2019

${ }^{2}$ Universidade Municipal de São Caetano do Sul - E-mail: fabiana_vi@yahoo.com.br

${ }^{3}$ Universidade Municipal de São Caetano do Sul - E-mail: anaparicio@uol.com.br
} 
La investigación es cualitativa de carácter colaborativo intervencionista y los datos considerados para el análisis son: registros de audio de las interacciones del investigador y profesor colaborador, grabación de vídeo de las clases, registros reflexivos en el campo Journal de la La investigación y las producciones escritas realizadas por los alumnos. Los resultados indican que la herramienta SD contribuyó significativamente a la Constitución de la autoría docente, así como al desarrollo profesional de los profesores colaboradores e investigadores.

Palabras clave: Secuencia didáctica del género textual. Alfabetización. Desarrollo profesional docente. Autoría docente. Carta al autor.

\section{Introdução}

Como o professor pode criar boas condições para o ensino e a aprendizagem da língua materna? Podemos dizer que os gêneros textuais colaboram muito nesse processo, agindo como articuladores das práticas sociais e dos objetos escolares que contribuem para a participação do educando na vida social e comunicativa. Para isso, o ensino da língua deve considerar as práticas sociais reais de comunicação.

Conforme os autores do Grupo de Didática de Língua Materna da Universidade de Genebra, o gênero é considerado "o instrumento de mediação de toda estratégia de ensino e o material de trabalho, necessário e inesgotável, para o ensino [...]" (DOLZ; SCHNEUWLY, 2004, p. 44). Dessa maneira, para o ensino da língua materna, consideramos importante que o professor planeje diferentes propostas significativas de produção escrita, diversificando os gêneros textuais.

Partindo dessas considerações, sustentamos que o trabalho com os gêneros textuais, por meio do dispositivo didático Sequência Didática (doravante SD), é valioso no contexto da alfabetização, pois contribui para que o professor possa acompanhar e intervir no processo de alfabetização, de forma mais assertiva, desde o momento em que o aluno começa a escrever seus primeiros textos. A SD pode colaborar funcionando como um instrumento de ensino que orienta as ações docentes na construção de situações de aprendizagem, de acordo com os conhecimentos e dificuldades reais dos alunos; e como um instrumento de formação docente uma vez que exige a criação e elaboração de dispositivos didáticos que vão além da tarefa de colocar em prática os materiais disponíveis, como os livros didáticos, por exemplo.

No presente artigo, apresentamos e discutimos resultados parciais da pesquisa que desenvolvemos sobre o processo de construção do dispositivo didático $\mathrm{SD}$, mais especificamente os resultados da análise do desenvolvimento profissional e autoria docente, considerando a constituição da parceria formação entre a professora pesquisadora e a professora colaboradora.

Para isso, organizamos o artigo em quatro seções. Na primeira seção, apresentamos como construímos os pressupostos teóricos da investigação. Na segunda, descrevemos a metodologia e o processo de geração dos dados da pesquisa. Na terceira seção, apresentamos o processo de construção colaborativa da SD da pesquisa e, na quarta, tratamos das contribuições analisadas durante esse processo. Finalizamos o artigo com as conclusões referentes aos resultados da análise. 


\section{Sequência didática: um caminho para aprendizagem do aluno e formação docente}

Entendemos que, na alfabetização, o aluno pode ser protagonista de sua aprendizagem, por meio do resgate à voz para a constituição do ser social e para possibilitar a constituição da autoria na escola. Dessa forma, é importante que o professor realize um trabalho em sala de aula que faça sentido para os alunos e os levem a construir as habilidades necessárias à produção de textos de um determinado gênero.

Em consonância com essa ideia, pesquisadores do grupo de Genebra (DOLZ; SCHNEUWLY, 2004; entre outros) e seus colaboradores brasileiros (MACHADO; CRISTÓVÃO, 2006; NASCIMENTO, 2009; entre outros) vêm realizando pesquisas sobre a $\mathrm{SD}$, com o objetivo de produzir conhecimentos que contribuam para o ensino da língua materna e conduzam o professor a se apropriar da proposta com vistas ao desenvolvimento do protagonismo docente na elaboração, por conta própria, de novas SD.

A SD é definida por Dolz, Noverraz e Schneuwly (2004, p. 82) como "[...] um conjunto de atividades escolares organizadas, de maneira sistemática, em torno de um gênero textual oral ou escrito". Trata-se de um dispositivo que oferece ao professor possibilidades de organizar atividades a fim de levar o aluno a ampliar seus conhecimentos sobre os gêneros textuais, de forma flexível e considerando a realidade de sua turma sempre relacionada a um contexto sociocomunicativo.

Segundo os autores genebrinos, a estrutura base de SD é organizada em quatro etapas básicas denominadas: apresentação da situação, produção inicial, módulos e a produção final, conforme o esquema ilustrado a seguir.

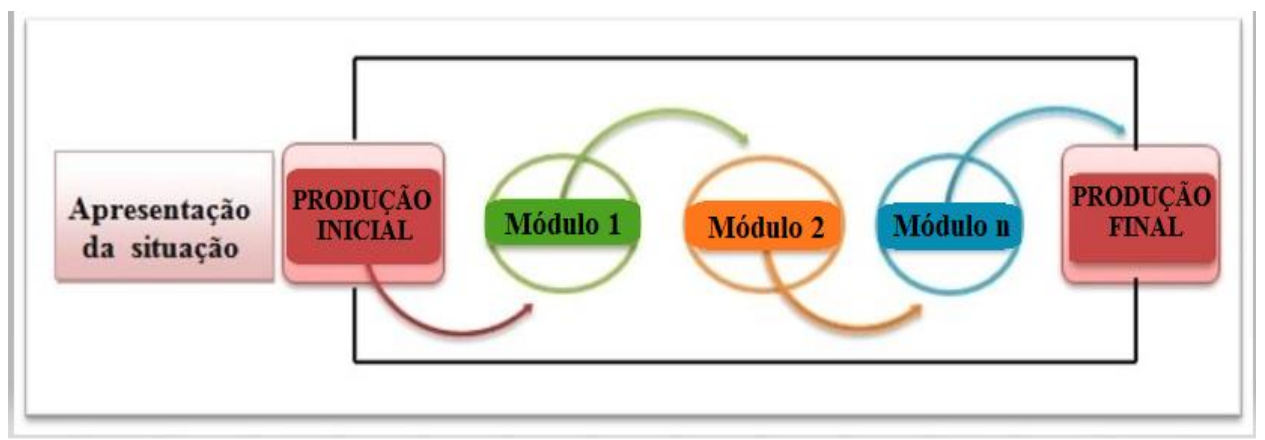

Figura 1. Estrutura base de SD

Fonte: Esquema da SD adaptado de Dolz, Noverraz e Schneuwly (2004, p. 83).

A “apresentação da situação" é o momento inicial da SD quando o professor expõe aos alunos o projeto de comunicação que será realizado efetivamente na produção final. Nesse momento, é essencial oferecer aos alunos uma consigna clara e objetiva, que deve indicar: qual é o gênero que será trabalhado, os objetivos da produção, para quem vai escrever, para quê, como e onde vai circular a produção, ou seja, os elementos do contexto situacional que envolve o projeto de comunicação. 
Em seguida, os alunos são convidados a realizar a "produção inicial", sendo a escrita do gênero com as representações iniciais que os alunos formularam da situação apresentada na consigna. Essa primeira produção permite ao professor verificar quais são os conhecimentos e dificuldades dos alunos em relação ao gênero de texto proposto, para que possa, então, planejar novas situações didáticas na etapa seguinte, a dos chamados "módulos". Esses módulos são atividades planejadas de acordo com os problemas que surgiram na primeira produção.

Podemos dizer que são exercícios criados para contribuir com avanços em diferentes capacidades de linguagem relacionadas ao gênero em questão. A última etapa da SD é a "produção final", momento em que os alunos retomam a própria produção inicial e colocam em prática, nessa elaboração da versão final, os conhecimentos construídos durante os módulos, propiciando ao aluno e ao professor avaliar quais foram os avanços. Dessa forma, esse dispositivo funciona como um instrumento de ensino, que permite ao professor desenvolver as melhores estratégias e novas formas de identificar quais são as capacidades e dificuldades dos alunos. Ao mesmo tempo, ajuda o aluno a ver o próprio texto como um objeto a ser retrabalhado e revisto, sendo a reescrita do próprio texto uma parte do processo de produção textual, possibilitando-lhe refletir sobre a própria língua e, consequentemente, aprimorar a sua escrita.

O trabalho com a SD no contexto da alfabetização pode propiciar condições ao aluno de se sentir mais confiante ao produzir seus textos e, assim, ocupar um lugar de autor em condições de produção significativas, mas também que o professor se torne mais autônomo, sendo capaz de refletir sobre suas práticas pedagógicas, tornando-as mais significativas, ou seja, criando as melhores situações de ensino para o desenvolvimento das capacidades de linguagem dos alunos.

\section{Os procedimentos metodológicos da pesquisa e a constituição da parceria formação}

Em relação à metodologia de pesquisa, apoiamo-nos na abordagem qualitativa, mediante a realização de uma pesquisa de cunho colaborativo-intervencionista (DAMIANI et al., 2013), a nossa participação como professora pesquisadora e a de uma professora colaboradora.

Em nosso trabalho, assumimos a postura do pesquisador da prática profissional, desenvolvendo uma pesquisa engajada, com a possibilidade de construir práticas e saberes novos, articulados aos processos de investigação em colaboração com outro professor. Assim, é conferido maior enfoque na formação do professor do que na mera coleta de dados, e a pesquisa é vista como instrumento de reflexão sobre a prática (ANDRÉ, 2015).

Essa ideia é também defendida por Cevallos e Passos (2012, p. 15) quando afirmam:

[...] o professor, ao pesquisar, demonstra iniciativa em romper com a hierarquização do saber entre a universidade e a escola. Nesse modelo, o professor não mais se restringe ao papel de fornecedor de dados que vai contribuir para o trabalho de 
outros pesquisadores, pois o curso possibilitou que o mestrando se envolvesse de forma crítica, nas diversas fases da pesquisa. Também possibilitou que fosse o protagonista em todas as atividades desenvolvidas e com um significado para ele. Além disso, os benefícios reverteram-se para a escola e para o seu desenvolvimento profissional.

Por isso, caracterizamos nossa pesquisa como qualitativa de cunho colaborativointervencionista, visando investigar as possíveis contribuições do dispositivo SD no desenvolvimento das capacidades de linguagem e autoria dos alunos, e do desenvolvimento profissional e autoria docente.

O caráter colaborativo vem do fato de que a professora colaboradora participa ativamente no progresso da investigação, numa interação constante com a professora pesquisadora em todo o processo de estudo, planejamento, elaboração, realização e avaliação da SD. Essa metodologia é defendida por Damiani (2008, p. 6), quando afirma que "[...] o trabalho colaborativo entre professores apresenta potencial para enriquecer sua maneira de pensar, agir e resolver problemas, criando possibilidades de sucesso à difícil tarefa pedagógica".

Dessa forma, a pesquisa colaborativa pretende provocar um processo de mudanças e melhorias na prática pedagógica e potencializar o desenvolvimento profissional de ambos. Conforme afirma Cabral (2013, p. 61):

[...] a pesquisa colaborativa cria condições favoráveis à mudança, à transformação da prática educativa, de um fazer espontâneo para um saber fazer consciente e conscientizador, com vistas à superação de problemas, à autorreflexão, à formação continuada e à produção do conhecimento científico.

Segundo Molina (2007, p. 66), na pesquisa colaborativa são observadas duas situações: “[...] integração do pesquisador na construção de projetos junto com o professor, no interior da escola, e a integração dos professores em investigações para a mudança da própria prática". Entendemos que essa parceria pode favorecer melhorias no ensino e aprendizagem.

Assim, a sequência didática foi realizada em classes de primeiro ano, na sala da professora colaboradora, e o processo de construção da sequência didática de gênero textual foi empreendido de forma compartilhada com negociações e tomadas de decisões conjuntas, numa ação de parceria entre professora pesquisadora e professora colaboradora.

Iniciamos o trabalho colaborativo estabelecendo o que denominamos de "Parceria Formação" com a professora colaboradora alfabetizadora, que se dispôs a participar de nossa pesquisa. Realizamos encontros quinzenais, de aproximadamente 2 horas-aulas para estudo e discussão de referenciais teórico-metodológicos, os quais tratam do ensino e aprendizagem de gêneros textuais e SD, bem como de documentos oficiais do contexto escolar focalizado: proposta curricular do município para a alfabetização, planos de ensino, entre outros materiais que pudessem contribuir com as nossas discussões.

Os estudos e as reflexões realizados visaram ao entendimento do dispositivo SD no trabalho com a produção de textos em sala de aula, orientado pela perspectiva dos gêneros textuais, considerando sua importância tanto para o desenvolvimento das capacidades de 
linguagem dos alunos, quanto para o processo de formação docente voltado ao ensino da língua materna.

Para melhor visualização e compreensão das atividades que realizamos nos encontros da Parceria Formação, elaboramos um quadro com a síntese do que foi trabalhado (Figura 2).

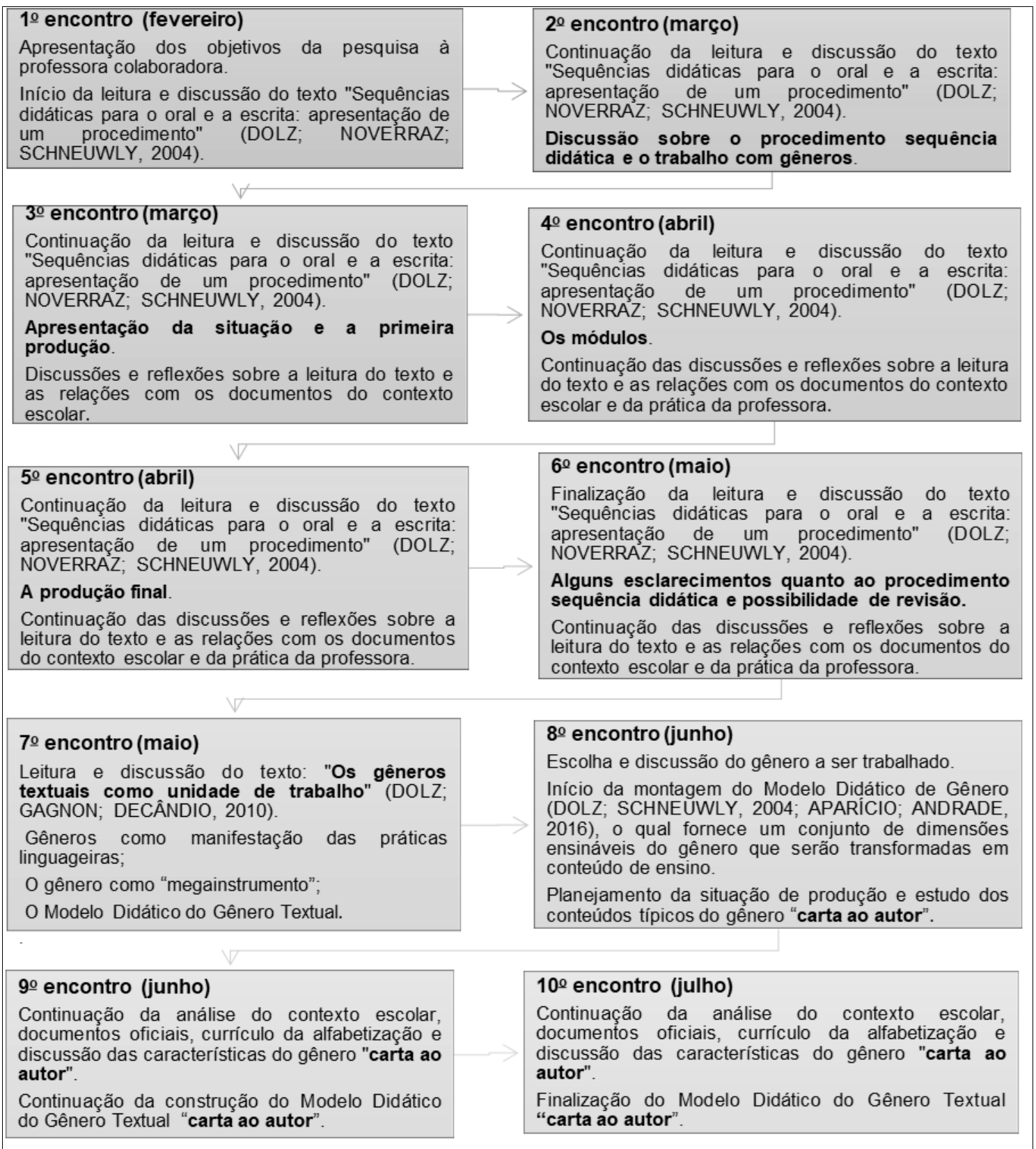

Figura 2. Síntese dos encontros da Parceria Formação

Fonte: Elaborado pela professora pesquisadora.

Nos encontros aprofundamo-nos na leitura dos textos, e começamos a estabelecer objetivos para a construção da SD. Pensamos em como criar situações em que o aluno fosse convidado a escrever textos autênticos em uma situação real de comunicação. Para isso, buscamos selecionar um gênero que fosse adequado a esse propósito, motivando os alunos a escrever. 
Ao longo dos meses, prosseguimos com a leitura do texto de Dolz, Noverraz e Schneuwly (2004) e de alguns documentos oficiais da alfabetização, como as Orientações Curriculares do munícipio, Parâmetros Nacionais Curriculares, Projeto Político-Pedagógico da escola e outros que contribuíram para a seleção do gênero e sua modalidade de ensino e as necessidades dos alunos. Após discussões desses documentos, escolhemos o gênero textual "carta ao autor", tendo em vista que poderíamos dar continuidade a um trabalho que já estava sendo desenvolvido com os alunos por meio da leitura do livro paradidático do autor Marcelo Loro "Tutuli em: que barulho é esse, papai?" (LORO, 2016) e, assim, criamos o Projeto "Cartas ao Autor".

Considerando, então, a importância de conhecermos muito bem o gênero textual "carta", quais as suas dimensões ensináveis, suas potencialidades para o ensino na alfabetização e as práticas sociais de referência desse gênero, que emergem em diferentes situações reais de comunicação, demos início à construção colaborativa de um modelo didático do gênero "carta ao autor", que contribuísse para a elaboração e o desenvolvimento da SD.

O modelo didático é considerado, pelo grupo de Didática das Línguas da Universidade de Genebra, uma ferramenta importante para o professor elaborar, organizar e orientar o ensino da produção textual, com o auxílio do dispositivo SD. Segundo Aparício e Andrade (2016), essa é uma tarefa de grande complexidade, que antecede e orienta a construção da SD, e necessita que o professor domine os conteúdos os quais serão ensinados para melhor seleção de aspectos do gênero a ser trabalhado, adequando-se às situações de aprendizagem, de acordo com as possibilidades e dificuldades dos alunos.

Para a elaboração do modelo didático, as autoras destacam a importância de o professor estudar e pesquisar para conhecer o gênero e suas características, elencando os elementos essenciais, por exemplo: analisar, em vários textos do mesmo gênero, as características da situação de produção (quem são o emissor e receptor e seu papel social, a quem se dirige, local e momento de produção e circulação, suporte, objetivo, tipo de linguagem etc.); identificar as capacidades de linguagem dos alunos, bem como suas necessidades e possibilidades de aprendizagem de acordo com a faixa etária, o nível de ensino; conhecer as orientações de documentos oficiais atuais para subsidiar o trabalho do professor com os gêneros textuais.

A frequência dos encontros da Parceria Formação possibilitou o diálogo e a reflexão por parte de ambas as professoras, com as discussões e a análise dos documentos oficiais, montagem do modelo didático de gênero, a montagem da grade de avaliação que confeccionamos a partir do planejamento das questões referentes às capacidades de linguagem e que serviu de parâmetro para o exame das produções dos alunos.

Com os estudos e reflexões que realizamos na Parceria Formação pudemos reconhecer a relevância do gênero "Carta ao autor" como uma forma de participação da vida social e comunicativa dos alunos, por criar situações que lhes estimulem a interagir com a língua escrita de modo significativo. Dessa forma, finalizamos a elaboração do modelo didático, o qual permitiu serem explicitadas as dimensões ensináveis do gênero "carta ao 
autor", isto é, os objetos de ensino a serem mobilizados na SD, bem como levantar as expectativas e as possibilidades de aprendizagem dos alunos em relação a esses objetos.

É importante destacar também que, ao longo de nossos encontros, surgiram situações de dúvidas em que a professora colaboradora demonstrava certa insegurança para trabalhar com a SD. Esse fato pode ser observado nos turnos das falas, transcritos a seguir, de um dos encontros da Parceria Formação.

Professora colaboradora - Mas nós iremos trabalhar a carta por muitas aulas, será que as crianças não vão se cansar? Pois costumo trabalhar diferentes gêneros a cada aula, e no terceiro trimestre já iniciamos as reescritas de contos e de fábulas.

Professora pesquisadora - Mas há uma diferença entre você trabalhar com os gêneros e trabalhar com os textos, certo?

Professora colaboradora - Como assim? Não entendi.

Professora pesquisadora - Quando trabalhamos apenas o texto, ou seja, a reescrita é apenas um exercício, olhamos apenas a estrutura e o sistema de escrita, mas com o trabalho com gênero, olhamos outros elementos e por isso temos que pensar em desenvolver as melhores condições de produção para a criança ter vontade de escrever, nós precisamos criar condições significativas, tendo um leitor-alvo para se tornar real, com um objetivo e cumprir com a finalidade.

Professora colaboradora - Ah, como na escrita da carta para o autor, pois ele vai receber essa carta.

Professora pesquisadora - Sim, assim a criança vai perceber-se como produtora de linguagem, pois vivenciou uma situação de comunicação real e nós vamos conseguir avaliar melhor o processo de aprendizagem dos alunos.

No trecho transcrito, podemos observar algumas crenças da professora colaboradora acerca do trabalho com as tipologias textuais. Tudo indica que a preocupação da professora é a "fixação" de estruturas e formas de organização dos textos. Não pretendemos aqui fazer uma crítica em relação a esse posicionamento da professora, e sim evidenciar a importância da construção compartilhada de conhecimento, que permite a troca entre os professores, avanços no processo de reflexão da prática e, consequentemente, a melhoria do ensino e do próprio desenvolvimento profissional docente.

Segundo Vaillant e Marcelo (2012, p. 216), “os docentes não são vasos vazios quando se envolvem em uma inovação. Já trazem ideias e crenças muito assentadas sobre o que é ensinar e aprender". Outro ponto importante desse trabalho colaborativo é a busca das professoras pelo mesmo objetivo de proporcionar melhorias ao ensino da língua na alfabetização, oportunizando momento de problematização das dificuldades por meio do diálogo. Portanto, concordamos que a colaboração "é um processo que pode ajudar a entender a complexidade do trabalho educativo e dar respostas melhores às situações problemáticas da prática" (IMBERNÓN, 2010, p. 65).

As interações e o trabalho colaborativo da Parceria Formação continuaram ocorrendo ao longo do desenvolvimento da SD, conforme será explicado na seção seguinte. 


\section{Da parceria formação à elaboração, desenvolvimento e realização dos módulos da SD "carta ao autor"}

A elaboração, desenvolvimento e realização da SD teve início no segundo semestre do ano letivo, como mostra o esquema a seguir (figura 3). Cabe ressaltarmos que, nesse momento, os alunos já se encontravam entre as hipóteses silábico-alfabética ou alfabética.

\begin{tabular}{|c|c|c|}
\hline $\begin{array}{l}\text { Agosto } \\
\text { Planejamento e elaboração } \\
\text { da apresentação da } \\
\text { situação de comunicação - } \\
\text { primeira produção. }\end{array}$ & $\begin{array}{l}\text { Setembro } \\
\text { Realização } \\
\text { apresentação da situação } \\
\text { e produção inicial - } \\
\text { análise das produções } \\
\text { iniciais e módulo 1 e 2. }\end{array}$ & $\begin{array}{l}\text { Outubro } \\
\text { Continuação das análise } \\
\text { das produções iniciais e } \\
\text { montagem dos módulos } 3 \text {, } \\
4 \text { e } 5 \text {. }\end{array}$ \\
\hline$\checkmark$ & & \\
\hline $\begin{array}{l}\text { Novembro } \\
\text { Realização dos módulos } 3 \text {, } \\
4 \text { e } 5 \text {. } \\
\text { Planejamento e elaboração } \\
\text { da produção final. }\end{array}$ & $\begin{array}{l}\text { Dezembro } \\
\text { Entrega da carta ao autor. }\end{array}$ & \\
\hline
\end{tabular}

Figura 3. Síntese do processo de construção colaborativa da SD

Fonte: Elaborado pela professora pesquisadora.

Para a motivação dos alunos na escrita da produção inicial da carta ao autor, planejamos cuidadosamente a primeira etapa da SD, a "Apresentação da situação", isto é, a consigna da situação de comunicação, que foi definida como: escrever uma carta manuscrita para o autor do livro “Tutuli em: que barulho é esse papai?", a ser entregue em mãos, quando o autor vier visitar a escola.

Os elementos oferecidos durante a apresentação da situação de comunicação permitem que os alunos descubram o que sabem e quais são suas dúvidas. É nesse momento, portanto, que os alunos expressam por meio das produções escritas quais são as representações que têm a respeito do gênero e do projeto de comunicação em curso.

A produção inicial é como uma avaliação diagnóstica das capacidades reais de cada aluno da turma e contribui para o professor saber o que o aluno ainda não aprendeu a respeito de um conteúdo/assunto, no caso em questão o gênero "carta ao autor". Assim, a partir da análise da primeira produção, é possível verificar as dificuldades e conhecimentos prévios dos alunos para planejar intervenções no desenvolvimento da SD e acompanhar o processo de aprendizagem dos alunos.

$\mathrm{Na}$ realização dessa etapa da $\mathrm{SD}$, obtivemos 24 produções iniciais e, para a análise dessas produções, consideramos os seguintes itens, com base na proposta dos autores do Grupo de Genebra: contexto de produção, conteúdo temático, planificação/estrutura composicional do texto, textualização/elementos linguísticos e gramaticais, e estilo/autoria.

Para evidenciar essa análise, selecionamos uma produção (figura 4) que consideramos representativa do percurso da maioria dos alunos do primeiro ano, e também por trazer aspectos que são recorrentes em grande parte do corpus. 


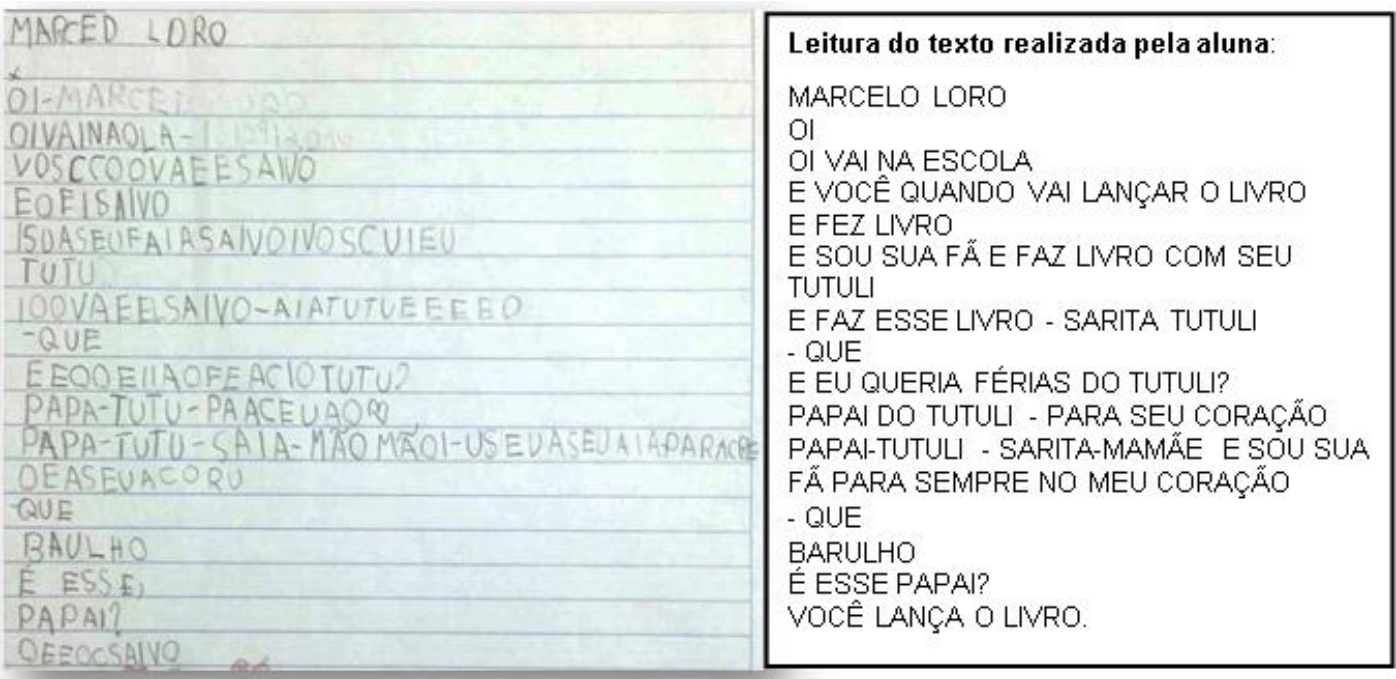

Figura 4. Produção inicial de uma aluna

Fonte: Arquivos da professora pesquisadora.

Quanto às condições de produção, como podemos observar, a aluna realizou a escrita da carta de acordo com sua hipótese de escrita (silábico-alfabética), buscando estabelecer a interlocução com o autor, dirigindo-se inicialmente à ele (MARCELO LORO) e em seguida a saudação (OI), e também assumindo a sua voz de emissora da carta expressando-se (EU SOU SUA FÃ). Tudo indica que a aluna tem muito a dizer ao autor (se ele vai na escola, quando vai lançar o livro, fazer um livro com a Sarita...); porém, a sua escrita tem trechos incompreensíveis, e o conteúdo não é apresentado em uma sequência lógica, comprometendo a leitura e a compreensão do texto.

Quanto à planificação/estrutura composicional do texto, aspecto que se relaciona com a mobilização de elementos e recursos característicos do gênero, percebemos que a aluna segue adequadamente a direção da escrita, porém não apresenta bom alinhamento do texto, pois não utiliza a linha até o fim, por realizar a escrita em forma de lista. Também não apresenta espaço entre as palavras, o que permite afirmar que ela ainda está em processo na utilização das noções iniciais de pontuação. No que se refere ao estilo e à autoria, nos trechos em que a escrita é legível, há indícios de autoria da aluna, como na pergunta "QUANDO VOCÊ VAI LANÇAR O LIVRO" e na expressão "SOU SUA FÃ".

De modo geral, na análise das produções, observamos que os alunos buscaram, de alguma forma, atender à consigna, aos objetivos da produção, isto é, à situação de comunicação proposta: escrever uma carta manuscrita à Marcelo Loro, autor do livro que leram, expressando suas ideias, opiniões, indagações e sugestões ao autor. Mesmo sem apresentar características do gênero "carta", cada aluno produziu de acordo com as capacidades de linguagem de que já dispunha.

Após a análise da primeira produção, o terceiro momento é o desenvolvimento dos Módulos, que são atividades planejadas pelo professor, a partir da análise da produção inicial, 
em forma de oficinas que possuem objetivos claros e visam ajudar a superar as dificuldades encontradas pelos alunos na produção inicial.

O processo de planejamento e desenvolvimento dos módulos é complexo, pois cabe ao professor verificar as aprendizagens e dificuldades dos alunos, avaliando de forma processual e contínua as suas capacidades de linguagem, relacionadas à produção do texto em questão.

Elaboramos, então, os módulos, criando condições para a construção de conhecimentos da língua, por meio de várias atividades e exercícios adequados ao contexto da alfabetização, e com a preocupação de contemplar diferentes objetivos e níveis de problemas apresentados nas produções iniciais dos alunos, oferecendo-lhes a oportunidade de conhecer os instrumentos necessários para o domínio do gênero "carta ao autor". No quadro 1 explicitamos detalhadamente o que foi realizado em cada um dos módulos.

Quadro 1. Sinopse das atividades planejadas na SD carta ao autor

Módulo 1 - Atividade de comparação entre os gêneros textuais - a professora realizou a leitura de diversos bilhetes e cartas e, a partir da observação dos dois gêneros, os alunos foram provocados a expor suas ideias e questionamentos.

Objetivo: Identificar, com o apoio da professora, a diferença entre os elementos da escrita de um bilhete e uma carta e reconhecer a função da carta no contexto da história "O carteiro chegou" (AHLBERG, 2007).

Módulo 2- Atividade para assimilação das características do gênero "carta", por meio de roda de conversa, uso da lousa digital e leitura de diferentes tipos de carta.

- Atividade de escrita colaborativa, em que a professora foi a escriba, para exercício e compreensão da estrutura composicional do gênero "carta".

Objetivos: Reconhecer a organização das partes e dos elementos da carta (Data e lugar, destinatário, saudação inicial, assunto, saudação final, assinatura); perceber as características recorrentes desse gênero em vários tipos de cartas e produzir colaborativamente uma carta coletiva ao autor fazendo uso dos aspectos discutidos na aula.

Módulo 3- Atividade de produção em dupla de uma carta a um outro autor que tenham lido, com o objetivo de ampliar o repertório dos alunos em relação ao conteúdo da produção.

Objetivo: Produzir em duplas uma carta tendo por referência o estudo e as discussões das aulas anteriores.

Módulo 4 - Atividade de observação e análise coletiva dos textos produzidos pelas duplas, digitalizados e projetados na lousa digital, com a finalidade de elaboração da lista de constatações a partir das descobertas e reconhecimento do que é importante para a produção de uma carta.

Objetivo: Analisar as produções com os alunos e produzir, colaborativamente, uma lista de constatações a partir das descobertas do que faltou nas produções e do que acharam interessante na escrita da carta ao autor.

Módulo 5 - Atividade de produção da escrita individual e espontânea com o propósito comunicativo de uma carta ao Papai Noel para ser exposta no painel da sala, com o intuito de capitalizar o que foi apreendido nos módulos e entregar aos pais no dia da reunião.

Objetivo: Utilizar a lista de constatações para a produção individual de uma carta ao Papai Noel. O principal objetivo aqui era observar se os alunos utilizariam o que haviam aprendido sobre carta, aplicando em um outro contexto diferente da "carta ao autor". Essa é uma das funções dos módulos.

Fonte: Elaborado pela pesquisadora. 
Diante de todos os módulos realizados na SD, era necessário verificar se os objetivos foram alcançados e, conforme explicam Dolz, Noverraz e Schneuwly (2004, p. 90), esta é “a possibilidade de pôr em prática as noções e os instrumentos elaborados separadamente nos módulos".

Foi importante relembrar com os alunos todos os elementos essenciais para a escrita de uma carta, a partir de uma lista de constatações. Depois, entregamos aos alunos a primeira produção, para que a observassem e a analisassem com base no que aprenderam nos módulos. Logo em seguida, com a mesma consigna atribuída na primeira produção, os alunos foram orientados a retomar e reler a primeira carta ao autor, e reescrevê-la, colocando em prática suas aprendizagens.

E, assim, com as suas produções iniciais em mãos, as crianças iam lendo e percebendo que na carta inicial faltavam alguns elementos da carta e outras sentiam que queriam mudar o assunto e que tinham novas ideias como notamos na produção final exemplificada na figura 5.

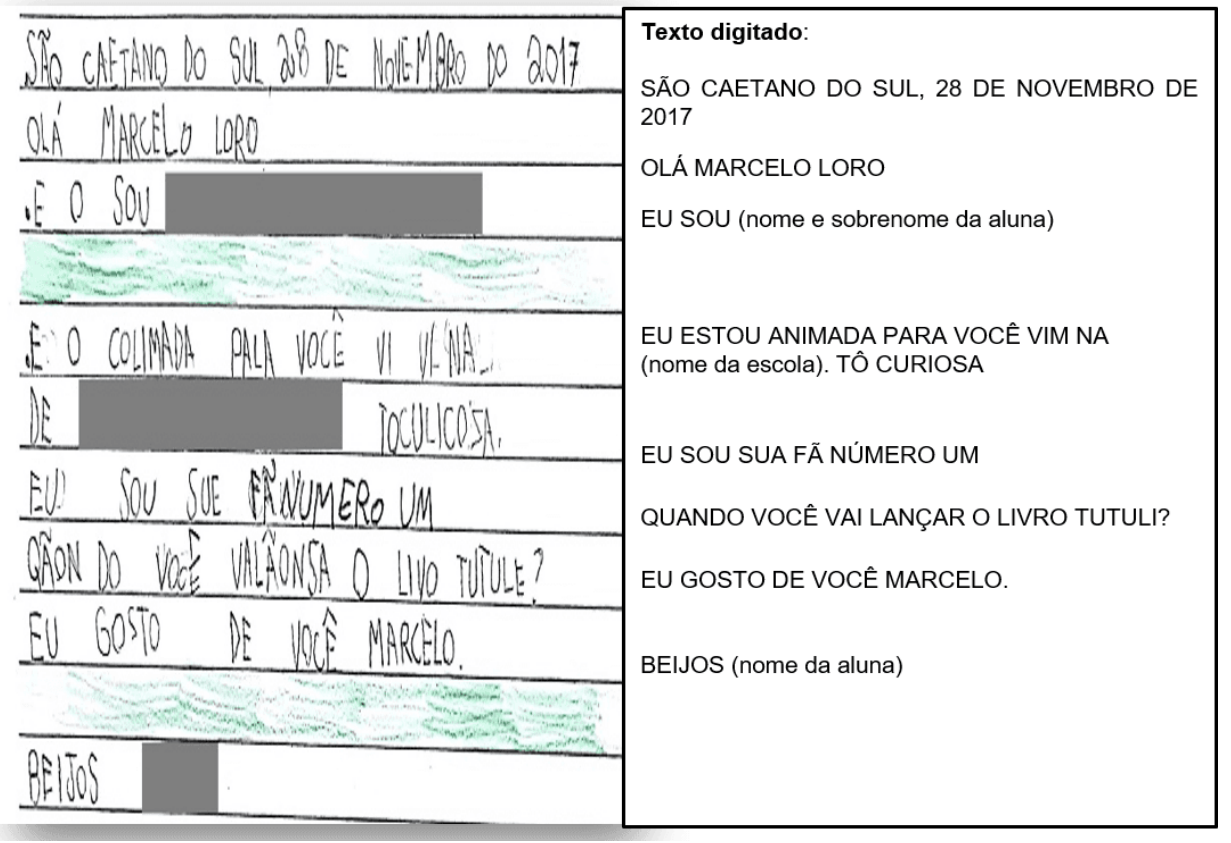

Figura 5. Produção final de uma aluna

Fonte: Arquivos da professora pesquisadora.

Analisando a produção final da aluna, verificamos que ela compreendeu melhor o contexto de produção, produzindo um texto mais apropriado aos objetivos solicitados na consigna atribuída pela professora. Isso pode ser observado quando a aluna mobiliza características do contexto de produção; no início, dirigindo-se ao destinatário com uma saudação adequada ao contexto: "OLÁ MARCELO LORO” e, em seguida, apresenta-se como "EU SOU A (nome da aluna inteiro)".

Quanto ao conteúdo temático, percebemos que a aluna aborda um assunto mais pertinente aos objetivos da carta ao autor, expressando seus sentimentos e expectativas: "EU ESTOU ANIMADA PARA VOCÊ VIM NA (nome da escola). TÔ CURIOSA/EU SOU 
SUA FÃ NÚMERO UM/QUANDO VOCÊ VAI LANÇAR O LIVRO TUTULI?/EU GOSTO DE VOCÊ MARCELO". Podemos observar nessas passagens que a aluna se assume na escrita da carta em primeira pessoa do singular, e estabelece a interação com o destinatário da carta, em tom informal, fazendo uso de vocabulário mais adequado ao gênero em questão. Com esses aspectos, entendemos que a aluna demonstrou avanços nas capacidades de uso da língua, ou seja, produziu um texto adequado ao contexto, respeitando o que foi solicitado na consigna.

No que diz respeito à estrutura composicional do texto, notamos que a produção final se aproxima da estrutura do gênero "carta". Ou seja, a aluna organizou as partes da carta com local e data com dia, mês e ano (cabeçalho), saudação e vocativo, assunto (corpo do texto), despedida e assinatura, usando os recursos típicos do gênero, com uma boa conexão entre as partes da carta. Dessa forma, entendemos que a produção final da aluna demonstra avanços nas capacidades discursivas, na medida em que não mais apresenta o texto na forma de lista, e sim com estrutura e elementos do gênero "carta".

Quanto à textualização/elementos linguísticos e gramaticais, observamos que a aluna organiza seu texto em um só parágrafo, realizando a divisão de suas ideias em linhas. Além disso, ela apresenta bom espaçamento entre as palavras, diferentemente da produção inicial, porém ainda necessita de maior atenção em relação às noções de paragrafação e emprego da vírgula, por exemplo. A aluna utiliza algumas pontuações, como o ponto de interrogação e o ponto final, e observamos que ela já avançou na hipótese de escrita; em sua produção final já escreve alfabeticamente, porém realiza algumas trocas ("l" no lugar de " $\mathrm{r}$ "), como nas palavras "CURIOSA" e "PARA"; já faz o uso de acentuação nas palavras: "SÃO", "VOCÊ", "FÃ" e "OLÁ". Verificamos, portanto, avanços nas capacidades linguístico-discursivas da aluna.

Quanto à autoria, a produção final evidencia singularidades, quando ela expressa seus sentimentos: "EU ESTOU ANIMADA PARA VOCÊ VIM NA (nome da escola)/TÔ CURIOSA/EU SOU SUA FÃ NÚMERO UM". Além disso, observamos no texto a tentativa de estabelecer uma atitude responsiva, no momento em que a aluna considera a presença do outro (no caso o autor), utilizando o pronome de tratamento "VOCÊ", tornando-se visível e tendo responsabilidade em seu dizer, pois escolheu as melhores palavras, a ordem dos fatos e passou uma mensagem ao autor.

Em síntese, todos os alunos reelaboraram sua produção inicial, agregando os conhecimentos aprendidos durante os módulos. Assim como nas duas produções que apresentamos aqui, ao compararmos a produção inicial e a final de todos os alunos, verificamos que ocorreram avanços nas suas capacidades de linguagem e autoria.

Ressaltamos que, após a produção final, ainda oferecemos aos alunos a possibilidade de um momento de revisão do próprio texto. Isso os ajudou a perceberem suas dificuldades e corrigir alguns problemas em sua produção final, além de aprimorar a qualidade de seus textos. Dessa forma, consideramos a revisão um procedimento de grande importância para a reflexão da criança a respeito de sua própria escrita, mesmo antes da construção da base alfabética. 
Constatamos, portanto, que a experiência com o dispositivo SD foi de fundamental importância para a produção de textos autorais, possibilitando aos alunos situações de melhor planejamento do seu dizer, em uma situação real e contextualizada, lembrando aqui o princípio de que o ensino da língua materna necessita que sejam oferecidas condições de produção as quais façam sentido para os alunos, para que tenham que ler e escrever realmente.

A nosso ver, o processo de construção colaborativa de SD de gêneros textuais requer o reconhecimento dos professores participantes da pesquisa (pesquisador e colaborador) acerca da importância do domínio do conteúdo. Além disso, deve-se considerar a construção dos sentidos da prática pedagógica diante de situações concretas de ensino e aprendizagem por meio de observação, registro, reflexão sistematizada e com interações compartilhadas, e a postura investigativa, que é de grande relevância para o desenvolvimento profissional e comprometimento com a autoformação (APARÍCIO; ANDRADE, 2016).

\section{O desenvolvimento profissional docente e o processo de construção colaborativa da SD}

Ao término da SD "Carta ao autor", não podemos deixar de considerar o desenvolvimento profissional docente propiciado pelo trabalho colaborativo em nossa Parceria Formação. Um aspecto que muito contribuiu foi o fato de a professora colaboradora estar aberta, engajada e receptiva a (re)construir suas ações, diante de todo o processo de construção colaborativa da SD, refletindo durante esse processo sobre novos contextos para o ensino da língua escrita. Contudo, vale ressaltar que vivenciamos situações na Parceria Formação que foram revestidas de tensões e (des)articulações de suas próprias crenças. Conforme aponta Marcelo (2009, p. 14):

o desenvolvimento profissional pretende provocar mudanças nos conhecimentos e crenças dos professores. Por sua vez, a mudança nos conhecimentos e crenças provoca uma alteração das práticas docentes em sala de aula e, consequentemente, uma provável melhoria nos resultados da aprendizagem dos alunos.

E isso podemos observar no trecho transcrito no fechamento da SD:

Professora pesquisadora: como terminamos esse processo de construção da sequência didática, gostaria que você relatasse o que sentiu, o que achou interessante e o que percebeu durante as suas aulas com a utilização do dispositivo sequência didática.

Professora colaboradora: eu vou te falar o que eu senti. É muito confortável você receber um projeto pronto. É muito confortável! Você recebe o projeto pronto todo ano, é aquilo, você já tem as atividades prontas, só que a sala de aula que você recebe não é a mesma. As crianças pensam diferente, eles vêm com a cabeça mil anos luz a tua frente e, se você deixar, eles te enrolam. Outra coisa que eu achei significativo é que no começo a gente fica assustada, mas depois a gente começa a ficar empolgada, porque comecei a ver que o interesse vai aparecendo e percebi o desenvolvimento das crianças. Realmente saem daquela história de estar sempre recebendo e com a sequência didática elas começam a falar, começam a questionar: "como eu escrevo isso, como eu faço aquilo? Professora, eu queria escrever tal palavra [...]". Às vezes, uma palavra totalmente diferente. Elas querem se colocar 
dentro do texto que estão fazendo. Então, percebi que os pequenos detalhes, como uma régua, podem empoderar as crianças. A minha fala com os meus alunos depois desse projeto mudou muito: eu digo para eles virem na lousa, quem vai vir escrever, também estou pensando mais nas minhas consignas. Agora dou mais liberdade para eles tentarem executar as atividades e depois vamos para a lousa para corrigir e assim vou escolhendo e principalmente aquelas crianças que dentro daquela situação possuem alguma dificuldade e assim consigo mediar. Os alunos vão ganhando mais confiança, segurança e não ter medo de escrever e se colocar. Com a sequência didática, tive a sensação que dá e que estou conseguindo fazer com que realmente se apaixonem por ler e escrever. É diferente. Percebi a vontade para escrever a partir do contexto em que a criança tem interesse. Também uma coisa que eu achei interessante é que percebi avanços na questão da oralidade, pois nós, professores, temos a mania de achar que o aluno tem que ficar em silêncio na sala de aula, mas se o aluno não fala, como ele vai escrever? Se ele não coloca as ideias dele para fora, como ele vai escrever? Se ele não interage e expõe a ideia, como vai começar a argumentar, a se colocar? O aluno precisa falar. Com esse projeto, os alunos se sentiram desafiados a resolver uma situação e a pensar como eu escolho as palavras que eu quero colocar no texto. Aprendi que temos que proporcionar momentos de discussão e de diálogo. Uma vez que permitimos que todos falem no momento da aula, todos começaram a entender que têm o direito de falar, e percebi que agora, quando eu coloco a turma para trabalhar em duplas e grupos, começaram a questionar e se colocar mais. Isso é bom para a vida.

Diante das palavras da professora colaboradora, no final do Projeto "Cartas ao Autor", verificamos uma transformação de suas concepções e práticas, como descrito em seu relato. Essa transformação se deu, entre outros aspectos, pela constituição do trabalho colaborativo, associado aos saberes teóricos apreendidos sobre funcionamento da linguagem escrita, por meio da construção do Modelo Didático do gênero textual "carta", e da vivência da experiência no processo de construção colaborativa da SD. Esses fatores possibilitaram à professora realizar em sala de aula novas práticas, na criação de contextos reais de leitura e de uso da língua escrita, e de melhorias no ensino e aprendizagem das crianças. Tudo isso propiciou o desenvolvimento profissional de ambas as professoras e a constituição da autoria docente.

Com base em Mizukami (2006) ao citar Shulman (1996), podemos entender que o nosso desenvolvimento profissional, com a realização desta pesquisa, está relacionado às seguintes ações formativas: ampliação da base de conhecimento (conhecimento específico do conteúdo); pedagógico geral e pedagógico do conteúdo (no nosso caso com os estudos prévios realizados na Parceria Formação); construção/criação de estratégias formativas (que podemos relacionar ao trabalho colaborativo na construção da SD); constituição de comunidades de aprendizagem (na constituição da Parceria Formação dentro do contexto escolar) e na atitude investigativa (no processo de reflexão e transformação na e sobre a ação prática, além do engajamento de ambas as professoras no projeto).

Como resultado do processo vivenciado na construção colaborativa da SD "Carta ao autor", elaboramos um material de apoio, chamado "Caderno Didático",i , voltado ao professor alfabetizador, para que sirva como referência ao trabalho com a SD em sala de aula. O Caderno está disponibilizado como um material didático digital navegável, em formato $e$ book, de arquitetônica vazada sendo de acesso público e gratuito. Esse material está acompanhado de sugestões e dicas de leitura de diferentes objetos digitais (textos e vídeos) e tem como base o percurso que realizamos em nossa pesquisa, fornecendo aos professores 
alfabetizadores possibilidades de utilização do dispositivo SD do gênero textual "Carta ao autor", de modo a desenvolver as capacidades de linguagem e autoria dos alunos, por meio de exemplos de situações vivenciadas em sala de aula, sugestões de atividades de natureza teórico-metodológica e práticas que podem orientar o processo de elaboração e aplicação da SD de gêneros textuais nos anos iniciais, especificamente, na alfabetização contribuindo para o desenvolvimento profissional docente do professor alfabetizador e para que sejam reconhecidas as possibilidades de utilização do dispositivo SD de gêneros na alfabetização.

\section{Considerações finais}

Com o processo de construção colaborativa da SD é possível considerar, de acordo com a análise dos resultados de tal experiência, que nossa pesquisa de natureza colaborativa intervencionista:

- promoveu o procedimento de reflexão na e sobre a ação da prática, com o engajamento da professora colaboradora e da pesquisadora, na busca de informações e melhorias na prática pedagógica, por meio do estudo no contexto escolar;

- ajudou as professoras na construção de novas aprendizagens, mediante o trabalho colaborativo e a Parceria Formação, que proporcionaram a realização de atividades mais significativas e a construção do conhecimento sobre a prática pedagógica, à medida que a professora colaboradora deixava de ser uma mera consumidora de materiais e se tornava autora, por meio do seu comprometimento com o processo de vivenciar e elaborar a SD, sendo produtora de seu próprio material de ensino, mais contextualizado e produzido de acordo com a realidade da turma;

- favoreceu o ensino e o aprendizado dos alunos em fase de alfabetização, com os avanços nas capacidades de linguagem e da produção autoral, tendo como base as comparações entre as produções iniciais e as finais dos alunos.

Sendo assim, o trabalho com o dispositivo SD contribuiu não apenas para o desenvolvimento da autoria dos alunos, mas também de autoria docente, pelo fato de a professora colaboradora e pesquisadora poderem protagonizar ao construir a SD, elaborar as atividades dos módulos, decidindo sobre as atividades e os recursos que consideraram mais adequados para que os alunos pudessem desenvolver suas capacidades de linguagem e autoria.

Com base nessas considerações, podemos concluir que o trabalho colaborativo possibilitou o pensamento crítico sobre o fazer pedagógico e a autoria docente, por meio da reflexão do desenvolvimento de uma postura mais investigativa, mediante estudos e a prática compartilhada. Tudo isso de maneira a superar desafios de sala de aula e, consequentemente, contribuir para o desenvolvimento profissional docente de ambas as professoras. 


\section{Referências}

AHLBERG, Allan. O carteiro chegou. Tradução Eduardo Brandão. São Paulo: Companhia das Letrinhas, 2007. 32p.

ANDRÉ, Marli Eliza Dalmazo Afonso de. Pesquisa, formação e prática docente. In: ANDRÉ, Marli Eliza Dalmazo Afonso de (Org.). O papel da pesquisa na formação e na prática dos professores. 12. ed. Campinas: Papirus, 2015. p. 55-69.

APARÍCIO, Ana Sílvia Moço; ANDRADE, Maria de Fátima Ramos de. A avaliação no processo de construção de sequências didáticas para o ensino da escrita nos anos iniciais do ensino fundamental: a formação do professor em foco. In: SILVA, Sílvio Ribeiro da; ALVES FILHO, Sebastião Carlúcio. Sobre avaliação e ensino de línguas: (re)discutindo conceitos e (re)elaborando ações. Campinas: Pontes, 2016. p. 35-58.

CABRAL, Marilúcia Barros Lopes. Formação docente e pesquisa colaborativa: orientações teóricas e reflexões práticas. In: PONTES, Verônica Maria de Araújo; SILVA, Luzia Guacira dos Santos; BATISTA, Maria Carmem Silva (Orgs.). Trilhas pedagógicas. Curitiba: Editora CRV, 2013. p. 59-68.

CEVALLOS, Ivete; PASSOS, Laurizete Ferragut. O Mestrado Profissional e a pesquisa do professor. Revista Diálogo Educacional. Curitiba, v. 12, n. 37, p. 803-822, set./dez. 2012. Disponível em: goo.gl/uWfqtq. Acesso em: 10 mar. 2017.

DAMIANI, Magda Floriana. Entendendo o trabalho colaborativo em educação e revelando seus benefícios. Educar em Revista. Curitiba, n. 31, p. 213-230, 2008. Disponível em: goo.gl/uSnYjS. Acesso em: 23 mar. 2017.

DAMIANI, Magda Floriana et al. Discutindo pesquisas do tipo intervenção pedagógica. Cadernos de Educação. Pelotas, v. 45, p. 57-67, maio/ago. 2013. Disponível em: https://goo.gl/25wjjh. Acesso em: 23 mar. 2017.

DOLZ, Joaquim; SCHNEUWLY, Bernard. Gêneros e progressão em expressão oral e escrita - elementos para reflexões sobre uma experiência suíça (francófona). In: SCHNEUWLY, Bernard; DOLZ, Joaquim. Gêneros orais e escritos na escola. Campinas: Mercado de Letras, 2004. p. 35-60.

DOLZ, Joaquim; GAGNON, Roxane; DECÂNDIO, Fabrício. Produção escrita e dificuldades de aprendizagem. 1 ed. Campinas: Mercado de Letras, 2010. 112 p.

DOLZ, Joaquim; NOVERRAZ, Michèle; SCHNEUWLY, Bernard. Sequências didáticas para o oral e a escrita: apresentação de um procedimento. In: SCHNEUWLY, Bernard; DOLZ, Joaquim. Gêneros orais e escritos na escola. Campinas: Mercado de Letras, 2004. p. 81108.

IMBERNÓN, Francisco. Formação continuada de professores. Porto Alegre: Artmed, 2010.

LORO, Marcelo. Tutuli em: que barulho é esse, papai? São Paulo, [s.n.], 2016. 
MACHADO Anna Rachel; CRISTOVÃO, Vera Lúcia Lopes. A Construção de Modelos Didáticos de Gêneros: aportes e questionamentos para o ensino de gêneros. Linguagem em (Dis)curso - LemD. Tubarão, v. 6, n. 3, p. 547-573, set./dez. 2006. Disponível em: https://goo.gl/j9n2oZ. Acesso em: 23 mar. 2017.

MARCELO, Carlos. Desenvolvimento profissional docente: passado e futuro. Sísifo Revista de Ciências da Educação. Lisboa, n. 8, p. 7-22, jan./abr. 2009. Disponível em: goo.gl/mhUFQD. Acesso em: 16 dez. 2017.

MIZUKAMI, Maria da Graça Nicoletti. Aprendizagem da docência: professores formadores. Revista E-Curriculum. São Paulo, v. 1, n. 1, dez./jul. 2005-2006. Disponível em: https://goo.gl/zZccjC. Acesso em: 16 dez. 2017.

MOLINA, Rinaldo. A pesquisa-ação/investigação-ação no Brasil: mapeamento da produção (1966-2002) e os indicadores internos da pesquisa-ação colaborativa. 2007. 177 f. Tese (Doutorado em Educação) - Faculdade de Educação, Universidade de São Paulo, São Paulo, SP, 2007.

NASCIMENTO, Elvira Lopes. Gêneros Textuais. Da didática das Línguas aos objetos de ensino. São Carlos: Claraluz, 2009.

VAILLANT, Denise; MARCELO, Carlos. Ensinando a ensinar: as quatro etapas de uma aprendizagem. 1 ed. Curitiba: Editora da UTFPR, 2012. 242 p.

\section{Notas}

i O Caderno Didático encontra-se disponível no link: https://tinyurl.com/yceszgr4 ou https://drive.google.com/open?id=1KpnrIAiJfnvlLSDXifWjB3zhXOnhvgiO. Acessos em: 16 dez. 2017. 